\title{
Cataract Surgery Redesign: Meeting Increasing Demand, Training, Audit and Patient-Centered Care
}

\author{
Kim Lawrence Ah-See $\mathbb{D}^{\prime}$ \\ Andrew Blaikie $\mathbb{D}^{2}$ \\ Natalie Boyle ${ }^{3}$ \\ Jonathan Foulds ${ }^{3}$ \\ Catherine Wheeldon ${ }^{3}$ \\ Peter Wilson ${ }^{3}$ \\ Caroline Styles (I) $^{3}$ \\ Shona Sutherland ${ }^{3}$ \\ Roshini Sanders ${ }^{3}$
}

'Department of Ophthalmology, Princess Alexandra Eye Pavilion, Edinburgh, Scotland, UK; ${ }^{2}$ School of Medicine, University of St Andrews, St Andrews, Scotland, UK; ${ }^{3}$ Department of Ophthalmology, Queen Margaret Hospital, Dunfermline, Fife, UK
Correspondence: Kim Lawrence Ah-See Princess Alexandra Eye Pavilion, Edinburgh, Scotland, United Kingdom Email kim.ah-see@nhslothian.scot.nhs.uk
This article was published in the following Dove Press journal: Clinical Ophthalmology

Objective: The demand for cataract surgery in Fife (a well-defined region in southeast Scotland) was steadily increasing over 15 years. Cataract surgery was therefore being outsourced to meet demand with consequences on list mix, training needs, patient experience and staff morale. We aimed to redesign our services to meet local demand, retain a patientcentered service and continue to fulfil training needs.

Methods: We quantified cataract surgery delivery over an 18-month period: before, during and after redesign of services. We studied numbers of operations, trainee cases and number of outsourced cases. We also considered the economic implications of the redesign.

Results: We studied three periods (each of six months duration): before redesign (BR), redesign period (RP) and post-redesign (PR). Data were collected on total operation numbers, number of cases performed by trainees, and numbers performed out with normal working hours (weekend lists) and external providers. An economic analysis examined the cost of outsourcing cataracts during BR and RP and the costs of the redesign, including building, equipment and additional nursing staff.

Conclusion: Regional fulfilment of cataract surgery provision remains a continuous challenge within the NHS. We show that with minimal investment, smart redesign process and collaborative working, increased local provision is possible while fulfilling trainee needs and achieving the necessary clinical audits and national standards.

Keywords: cataract surgery, healthcare policy, training, service provision

\section{Introduction}

Cataract surgery represents $6 \%$ of all UK surgery, ${ }^{1}$ is cost effective, and achieves significant quality of life outcomes. However, the delivery of cataract surgery in the United Kingdom (UK) is facing a significant challenge within the constraints of a national public service. Visually significant elderly cataract is rising with a projected $20 \%$ growth in the number of those aged over 65 years by the year 2026. ${ }^{2}$ Patient expectations have also increased with the introduction of toric lenses achieving higher levels of unaided vision. The presence of coexisting disease, such as macular degeneration, is no longer an excluding criterion due to new sight saving treatment. The threshold for cataract surgery continues to fall and national directives support this process. National Institute for Health and Care Excellence (NICE) guidelines of $2017^{3}$ recommended that access to cataract surgery not be restricted on the basis of visual acuity and Scottish Governmental policy dictates that all patients have cataract surgery within 18 weeks referral. ${ }^{4}$ 
NHS Fife serves a population of approximately 400 000 people and the cataract surgery for the region is undertaken at the Queen Margaret Hospital (QMH) in Dunfermline. There are presently 8 consultants (five fulltime equivalents), undertaking 14 weekly cataract and mixed theatre lists. All subspecialities and related surgery are performed within the unit apart from vitreoretinal surgery. In 2002, the cataract service in QMH completed its first redesign ${ }^{5}$ and subsequently achieved the highest increase in rates of cataract surgery between 1997 and 2004 when compared with all other Scottish health boards. This represented a 71\% increase in operations in 2004 compared to $1997 .{ }^{5}$ Notably, there was a concurrent doubling in trainee cases. This redesign was cited by the Royal College of Ophthalmologists as best national practice at the time. ${ }^{5}$

Despite the first redesign in 2002, increasing need ${ }^{1}$ led to a widening gap between capacity and demand. For the first time in Fife, cataract surgery was outsourced to external providers performing weekend lists within the unit and outwith the region. Cataract patients were graded from one to four based on a system of preoperative risk stratification $^{6}$ and only grade 1 and 2 (the lower risk groups) were outsourced. This led to an unintended consequence for routine hours departmental surgery to be more populated with complex cases with less training opportunity. Dissatisfaction amongst trainees began to rise carrying the risk of losing them from the service and potentially impacting the on call rota and emergency care provision for the region. A domino effect was feared with creeping loss of services and staff combined with diminishing morale. Furthermore, the population of Fife was expected to increase by $32,000(8 \%)$ over the next 20 years, and management data estimated a minimum 3\% annual increase in cataract surgery representing an annual shortfall of 350-400 cases.

For all the reasons above there was a compelling incentive for further redesign of cataract services in Fife and in 2018 a successful bid was made. This paper describes this most recent redesign process and shows that with minimal investment we were able to increase throughput to meet local demand and retain training needs.

\section{Methods}

The provision of a sustainable and comprehensive cataract service for the population of NHS Fife was identified as a priority for the consultant body and a plan to achieve this was devised in collaboration with the managerial team.
A redesign team was brought together with a consultant lead, senior ophthalmology manager, theatre sister lead, ophthalmology charge nurse, business manager, statistician, theatre Information Technology (IT) analyst and estates officer. The primary aim of the redesign was to increase the number of cases performed annually to meet growing demand. All patients were to be operated on within the 18-week guarantee as stipulated by the Scottish government. The redesign group met weekly and an efficiency assessment of the cataract service was conducted at the start of the redesign process in January 2017. A key finding was that during a typical cataract theatre list there was enough time to increase the number of cases by two or three if the surgeon's time could be optimized and the turnover time between operations could be minimized. Another strategic finding was that the existing theatre space was large and could creatively be redesigned to offer two theatre spaces for simultaneous surgery. The proposed strategy to achieve this was coined a "Jack and Jill" (JJ) theatre arrangement, whereby a single surgeon works between two adjoining theatre rooms, so that preparation and clear-up can be performed simultaneously with surgery. Existing floor space in the cataract theatre was redesigned to build a second theatre room with a shared scrub area between the two theatres. All health board, bacteriology and sterility regulations were adhered to and incorporated into the rebuild.

An initial plan was agreed that there would be four $\mathrm{JJ}$ lists per week. A maximum of 14 and a minimum of 10 cases would be performed on these lists. The variation would depend on complexity of cases with grade 4 cataracts taking up two slots. Additionally, senior trainees on the list would not require list alteration but junior trainees would require a commensurate reduction in numbers depending on individual experience and capability. During the redesign period, general wards and theatres were utilized to continue with provision of cataract assessment and surgery. For this study, we quantified cataract surgery delivery over three periods of six-month durations: before redesign (BR), redesign period (RP) and postredesign (PR). Data were collected on total operation numbers, number of cases performed by trainees, number of anterior vitrectomies, numbers performed out-with normal working hours (weekend lists) and numbers outsourced to other standalone non-training providers. An economic analysis examined the cost of outsourcing cataracts during $\mathrm{BR}$ and RP, the costs of the redesign and the 
costs of increasing capacity to include increased nursing staff, instruments, microscope and consumables.

All data were entered in Microsoft Excel for analysis and interrogated by our IT department.

\section{Results}

Table 1 outlines the number of cataract operations performed in the three study periods each six months, before redesign (BR) during the redesign period (RP) and post redesign period (PR). There were 973 cataract extractions performed in BR compared to 1547 in PR representing an increase of $62.9 \%$. A total of 415 cases were outsourced over 12 months spanning through March 2018 and March 2019. Although there are more cases outsourced during RP, the arrangements for these breeched procedures were made in BR and only came to fruition in RP. This also applies to the 112 cases outsourced in PR, when arrangements for these cases were made in RP.

Trainees performed 150 cases as the principal surgeon in BR compared to 223 in PR representing an increase of $67.3 \%$. Only grade one and a small proportion of grade two cataracts were outsourced for cataract surgery. There were $13(1.3 \%)$ vitrectomies in the BR period, $5(0.5 \%)$ in the RP and $5(0.48 \%)$ in the PR period.

Table 2 outlines the economic analysis of the cataract redesign. The upfront costs for the redesign totaled $£ 738$ 110, broken down to $£ 565250$ for the rebuild, £112 850 for the microscope, $£ 38,000$ for the phacoemusification handpieces and $£ 22,000$ for the instrument trays. The ongoing and recurrent costs for extra nursing staff total $£ 60,408$ for theatre staff and $£ 29,860$ for cataract clinic staff.
Table 2 Economic Analysis of the Redesign

\begin{tabular}{|l|l|}
\hline Redesign Costs & $\begin{array}{l}\text { In Pound } \\
\text { Sterling (f) }\end{array}$ \\
\hline Cost of building work & 565,250 \\
Microscope & 112,850 \\
Hand pieces & 38,000 \\
Instruments and Trays & 22,000 \\
Total & 738,100 \\
\hline Recurring annual costs & \\
Nursing staff theatre & 60,408 \\
Nursing staff Clinic & 29,860 \\
Cost of outsourcing 4I5 cataracts (12 months) & 180,110 \\
\hline
\end{tabular}

A total of 415 cases were outsourced over 12 months at an average cost of $£ 434$ per case. This gives a total cost of $£ 180110$ for these cases.

At the biannual regional trainee assessment, a significant trainee feedback issue was the number of cataract surgery cases offered to trainees. The redesign enabled trainees to carry out the recommended annual numbers and well in excess of that required by the Royal College of Ophthalmologists.

In the three months just before opening the new JJ lists, there were six patient complaints to the cataract unit all pertaining to prolonged wait for surgery. In the three months after opening the new cataract suite, there were twenty patient letters of thanks and appreciation and no complaints.

\section{Discussion}

Our study shows the potent effects of a targeted and relatively inexpensive intervention to improve cataract

Table I Number of Cataract Surgeries Performed in the Three Study Periods

\begin{tabular}{|c|c|c|c|}
\hline & $\begin{array}{l}\text { Before Redesign (BR) } \\
\text { March 2018-August } 2018\end{array}$ & $\begin{array}{l}\text { Redesign Period (RP) } \\
\text { September 2018- } \\
\text { February } 2019\end{array}$ & $\begin{array}{l}\text { Post Redesign } \\
\text { (PR) } \\
\text { March 2019- } \\
\text { August 2019 }\end{array}$ \\
\hline Total cataract cases & 1033 & 1291 & 1659 \\
\hline Cases performed in QMH within normal hours & 973 & 1000 & 1547 \\
\hline $\begin{array}{l}\text { Cases performed in QMH outwith normal hours } \\
\text { (supplementary weekend lists) }\end{array}$ & 36 & 12 & 0 \\
\hline Cases outsourced (waiting list initiatives) & 24 & 279 & $112 *$ \\
\hline Cases outsourced to Golden Jubilee Hospital & 199 & & 0 \\
\hline Consultant cases & 823 & 892 & 1324 \\
\hline Trainee cases & 150 & 108 & 223 \\
\hline Anterior vitrectomies (\% of total cases) & $13(1.33)$ & $5(0.50)$ & $8(0.48)$ \\
\hline
\end{tabular}

Notes: *All within March 2019, the month immediately following completion of the rebuild. Arrangements for these breeched cases was made during the redesign period and in the post-redesign period, there was no further outsourcing required. 
service productivity in an NHS hospital setting. After a short transition period of six months, the department was able to increase the number of cataract cases completed by $62 \%$ and trainee cases by $67 \%$. This translated into reductions in waiting times with a patient referral to surgery time of 18 weeks or less and elimination of the requirement to outsource cataract surgery. This was achieved without any increase in medical manpower or expansion in the physical size of the unit. The result is that we provide a fully self-sustaining cataract service and at the time of current submission it is the only health board in Scotland not to outsource cataract surgery.

A strategic and collaborative plan with management found that a new build was not necessary but that with creative redesign the existing space could be modified for higher output. Identification that the turnover time was the greatest limiting step led to the concept of "Jack and Jill" lists. An understanding of the need for flexibility within the JJ lists with completion of 10 to 14 cases was key to retaining trainee experience and opportunities.

\section{Patient Satisfaction}

There is no doubt that speed to treatment is a paramount need for every patient. However, as cataract services modernize to meet demographic challenges, it is important that the doctor-patient relationship is preserved. Although generally very safe and successful, cataract surgery continues to carry a small but important risk to vision and can be a daunting process for many patients. Maintaining trust, rapport, and compassion is vital in these circumstances. This is crucial as the patient population becomes older and the incidence of ocular comorbidity such as glaucoma, macular degeneration and diabetic retinopathy become more common. The risk of suboptimal outcomes becomes even more important in these patient populations.

Fife is a geographically challenged area and patients are much more readily able to transport themselves to the local hospital compared to travelling across Scotland. This also places less reliance on relatives and time off work. Furthermore, any complications arising from outsourced cataract surgery were dealt with by the team at $\mathrm{QMH}$. This division of the surgery and ensuing complications between different teams carries the potential for suboptimal outcomes when patients are outsourced for their surgery and this is negated by local surgery provision. There remains considerable variation within Scotland and the UK on provision of first and second eye cataract surgery. Lowering the threshold for surgery by one Snellen line can have a profound effect on the numbers of surgeries required. ${ }^{7}$ In Fife, second eyes are treated in exactly the same way as first eyes based on studies that show improvements in visual acuities, stereopsis, patient-reported visual disability and confidence. ${ }^{8}$ A self-sustaining cataract service can also ensure that patients have both eyes operated on by the same team/surgeon with prior knowledge of first eye surgery performance.

\section{Training Implications}

Integral to the future of cataract surgery is the surgical training of young ophthalmologists. Cataract surgery requires significant training and expertise to be performed safely and efficiently. Studies have shown that a significant factor for operative complications is the operation being performed by trainees. ${ }^{9}$ The Royal College of Ophthalmologists expects trainees to complete 50 cases within the first two years and a total of 350 before concluding training. ${ }^{10} \mathrm{Au}$ et al have shown that "fast-track" cataract services may reduce the proportion of cases performed by trainees ${ }^{11}$ and the Way Forward report also warns against this development. ${ }^{12}$

A secondary focus of our study was to examine surgical training opportunities and we showed that increasing throughput did not compromise training. Indeed, trainee cases increased by $67 \%$ from the BR to the PR periods. A previous audit at QMH estimated that $80 \%$ of cases could be suitable for training. ${ }^{13}$ This clearly represents a rich training environment and indeed, QMH has successfully retained all trainee numbers over many years. There is evidence that the number of cases performed by UK ophthalmology trainees is stable at between 500 and 600 cases on average before the completion of training which compares favourably with trainees in other settings. ${ }^{14,15}$ The seven-year UK ophthalmology training scheme is held as a gold standard, although some argue for a shorter training duration with retention of required cataract surgery cases. ${ }^{16}$ The projected rising demand for cataract surgery makes it even more essential that a competent workforce is available to meet this in the coming years. Our experience in NHS Fife demonstrates that modest investment can meet rising demand while preserving a rich training environment.

\section{Staff Morale}

At the time of outsourcing cataract surgery, there was creeping dissatisfaction amongst consultants and trainees 
at the inability to provide suitable training, dealing with a higher proportion of the complex cataracts and managing postoperative complications in patients operated on elsewhere. It became more profitable both financially and in terms of "work hours" for both nursing and medical staff to perform outsourced rather than "in house" cataract surgery. These choice preferences had the potential for conflicts of interest, erosion of cohesive teamwork and reduced overall morale considered unhealthy for the longterm progress of the unit.

\section{Economics}

The approximate cost of outsourcing cataracts over a oneyear period was $£ 180110$. This was based on an average cost of $£ 434$ per case for the 415 cases. It is estimated that in the next ten years Fife would have to perform 300-400 cases more annually to keep up with demand. The average cost for a cataract procedure in NHS Fife is $£ 182$ per case. Thus, we expect that by fulfilling the needs of our patients locally we will have recouped the cost of the rebuild within three years. There were 574 'additional' cases undertaken in the PR compared to the BR period. The cost to outsource this number of procedures would have been $£ 249116$ which approximates to about half the cost of the rebuild. Furthermore, this analysis excludes the costs of the extra work hours spent by secretaries identifying and contacting patients suitable for outsourced cataract surgery as well as the increased travel time and cost to individual patients (and their relatives) who had to journey several hours to have their surgery.

\section{Overview of the QMH Model, Limitations and Future Developments}

The model of cataract pathway at QMH includes a onestop cataract clinic which receives referrals directly from optometrists and general practitioners (with optometry report), assessment by cataract nursing staff and finally a consultant decision about need for surgery. The cataract service at QMH has a history of excellence with the first redesign (in 2000) held as gold standard by the Royal College of Ophthalmologists. ${ }^{5}$ The unit pioneered electronic referral from primary care in 2007 with a dedicated cataract referral form which was subsequently rolled out across Scotland. ${ }^{17}$ Figure 1 displays this form which specifically asks questions on lifestyle, desire for surgery and whether the patient was in receipt of the cataract information booklet. This facilitated a high standard of referral information with less false-positive referrals. The unit also designed an inhouse cataract electronic patient record (EPR) that allowed for continuous cataract audit of patient and surgery factors, ${ }^{13}$ as well as collection of operation outcomes which could be compared to national standards and support consultant appraisal processes (Figure 2).

However, we continually strive to reduce the falsepositive referral rate with improved communication. And there are further refinements intended to our surgical service to increase the surgeon's time for surgery, such as in the processes around prescribing pre- and post-operative eye drops and obtaining patients' consent. This task is currently carried out by the medical staff, but accrediting specialist nurses to perform this duty could free up more time for surgery. There also remains a small but significant group of patients that are cancelled on the day of surgery and we continue to try to address the medical, social and transport factors contributing to this shortfall. To improve on the present study, formal surveys of the patient experience in the redesigned cataract service are planned. Similarly, formal surveys of the trainee experience in such high-volume cataract lists would be a useful addition.

Figure 3 shows the trend in cataract surgery within the fourteen health boards in Scotland and one external NHS provider board over ten years spanning 2009 to $2018 .^{18}$ The total number of cataract operations performed in Scotland rose from 33,000 to 44,000 representing an overall increase of $33 \%$. However, there remains a striking variability year upon year within each health board for a very commonly performed procedure. Explanations for this would include redefining geographical borders, consultant manpower variations and outsourcing of cataracts. Surprisingly, the visual acuity threshold for first and especially second eye cataract surgery is also variable across health boards and this practice has a profound impact on the numbers of cataract surgery required. In 2018 approximately $15 \%$ of all cataract surgery was outsourced across the 14 health boards and it is estimated that a similar number are carried out in the private sector.

There are examples in the international literature of similar and alternative strategies that have been employed to increase the availability and efficiency of cataract surgery. At the Aravind Eye Hospitals in India, there is a focus on optimizing the flow of patients through the service on the day of surgery, including having two operating tables in the same room, such that a patient can be prepared while the other is having surgery. ${ }^{19}$ This and other strategies to meticulously plan the day of surgery 


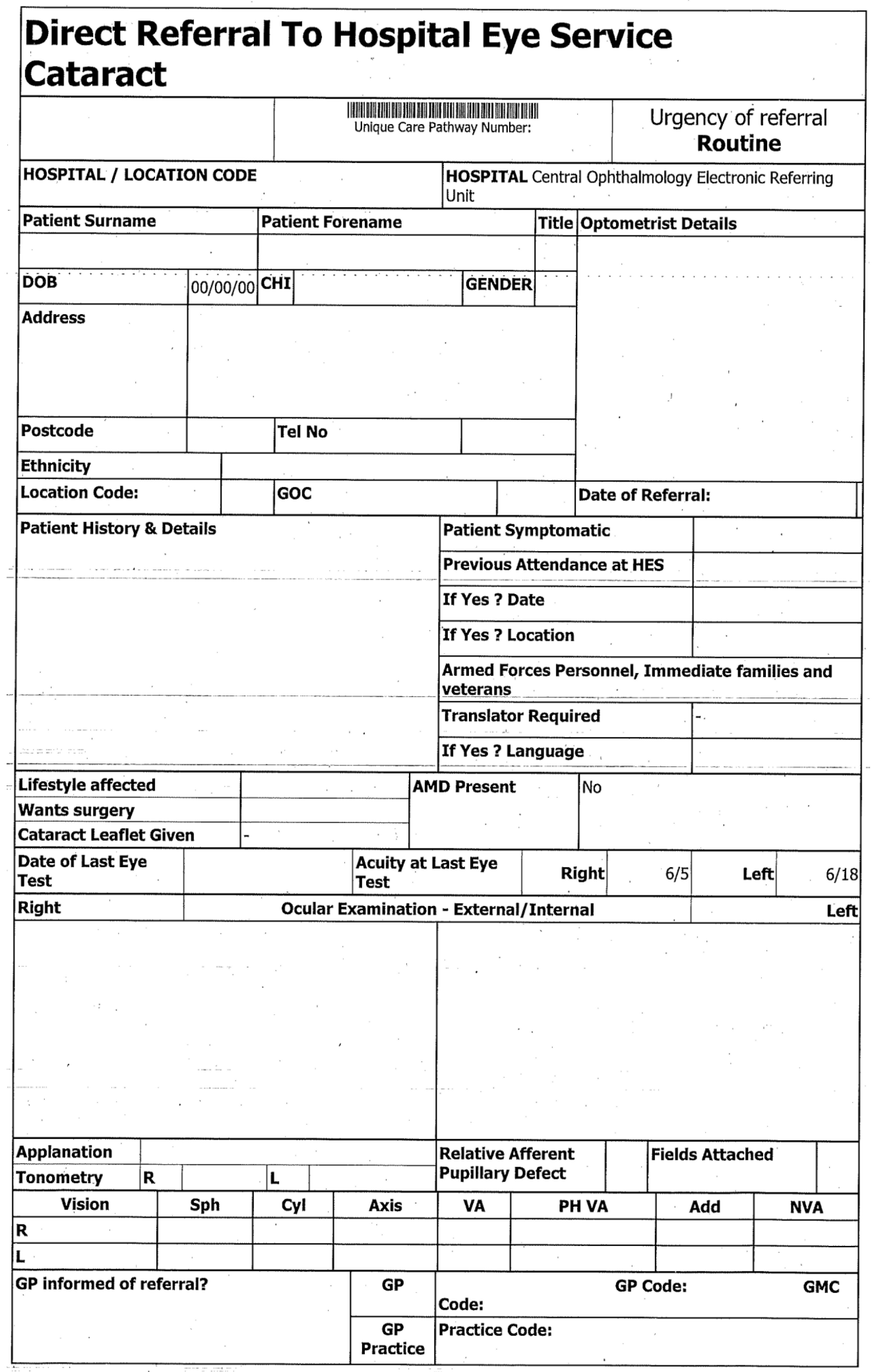

Figure I NHS Fife cataract referral form. 


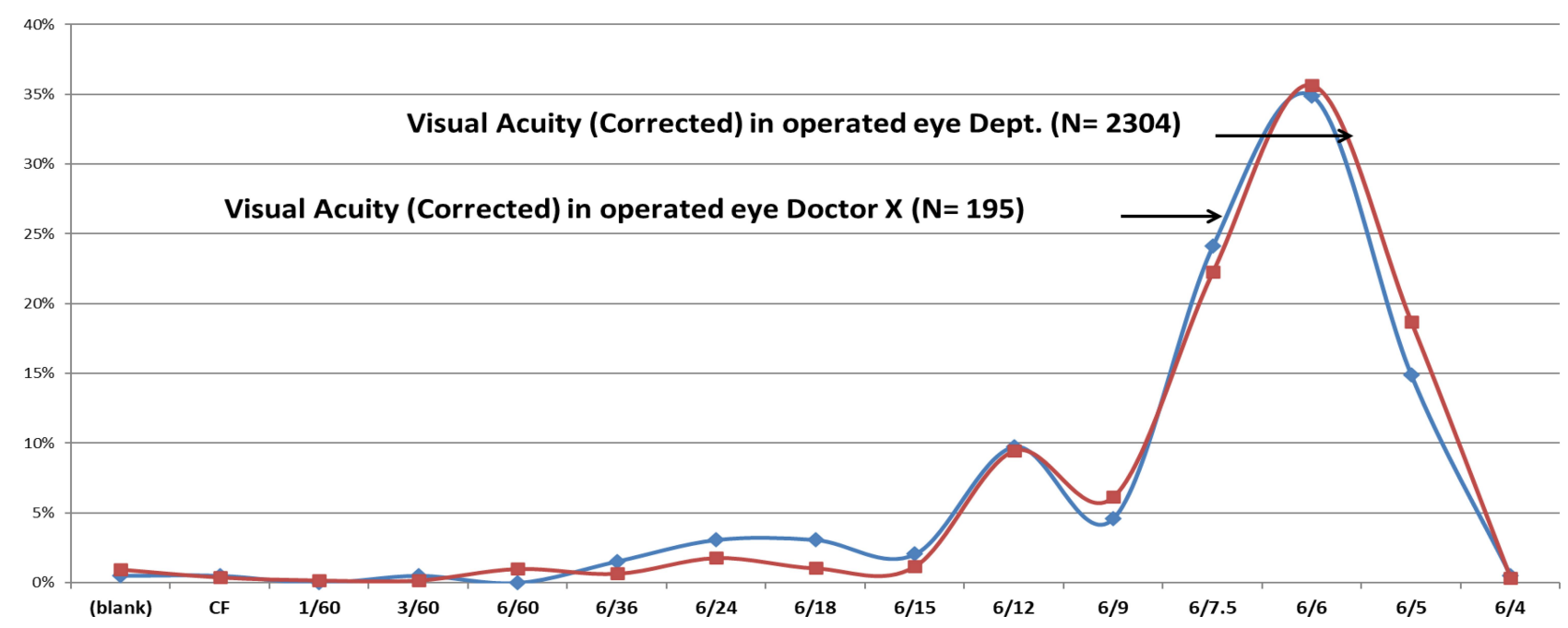

Figure 2 Post-operative visual acuity outcomes for QMH department (all surgeons) compared to Doctor X.

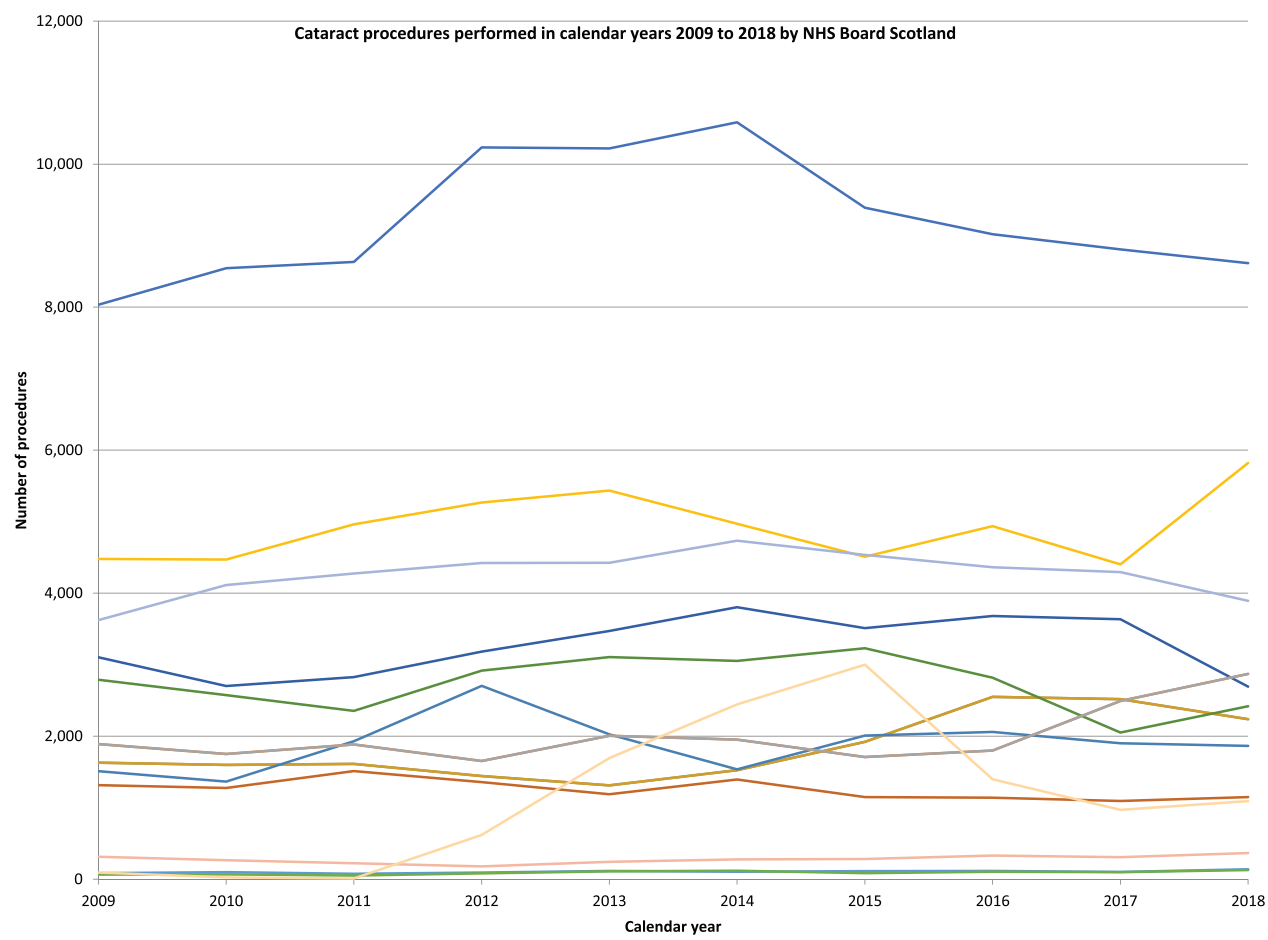

Figure 3 Cataract surgery procedures performed in calendar years 2009 to 2018 by NHS Board in Scotland, United Kingdom. From: Scottish Government. National Ophthalmology Workstream: Hospital Eye Services Progress, Priorities \& Practical Actions for a Safe, Sustainable Service across Scotland April 2017. ${ }^{18}$ Accessible at: https:// www.nhshighland.scot.nhs.uk/Services/Optometry/Documents/SGHD\%20National\%20Ophthalmology\%20Workstreams\%20HES\%20April\%2020I7.pdf.

has facilitated some high-volume surgeons completing around 80 procedures per day. ${ }^{20}$ There are further such examples of high-volume centres globally in both developed and developing settings where success has been found in tackling the burden of vision loss from cataract. Although practices such as those used in Aravind Hospitals might not be possible in settings like the United Kingdom or North America, our study shows how similar strategy ideas can be adapted and employed successfully in these settings.

The Way Forward project commissioned by the Royal College of Ophthalmologists (RCOphth) in $2015^{21}$ set about collating best practice guidelines to support the increasing demand for cataract surgery and reported on the global estimations that a $52 \%$ rise in cataract cases is to be expected between 2015 and $2035 .^{22}$ Unfortunately, available resources 
struggle to keep pace with this challenge and a survey from the RCOphth in April 2019 reported that, since the publication of the 2017 NICE guidelines, $62 \%$ of responding units continue to restrict access to cataract surgery. ${ }^{23}$

Cataract surgery continues to be rationed despite evidence that it remains the most cost-effective NHS operation. ${ }^{23}$ There is no single solution to this problem which needs tailored to local populations, resource and manpower. Our study demonstrates that with strategic planning, collaborative working and determination to retain local services, total cataract service provision was possible.

\section{Ethical Approval}

Ethical approval was not required for this study as no individual patient data was used.

\section{Acknowledgments}

Charge Nurses Ruth Robertson, Linda Barr and Catherine Jack, NHS Fife. Senior Management Team, Karen Wright and Murray Cross. Information Services Division Scotland, Chris Watling Scottish Government, Jacqui Dougall and John Connaghan.

\section{Disclosure}

All authors declare no conflict of interest: no support from any organisation for the submitted work; no financial relationships with any organisations that might have an interest in the submitted work in the previous three years; no other relationships or activities that could appear to have influenced the submitted work.

\section{References}

1. The Royal College of Ophthalmologists. The Way Forward Executive Summary. London; 2017.

2. Office for National Statistics. Overview of the UK population: November 2018. Available from: https://www.ons.gov.uk/peoplepopu lationandcommunity/populationandmigration/populationestimates/arti cles/overviewoftheukpopulation/november 2018 .

3. National Institute for Health and Care Excellence. Cataracts in Adults: Management. NICE guideline NG77; 2017.

4. Eighteen weeks: the referral to treatment standard. Edinburgh; 2008. Available from: www.scotland.gov.uk.

5. Tey A, Grant B, Harbison D, Sutherland S, Kearns P, Sanders R. Redesign and modernisation of an NHS cataract service (Fife 1997-2004): multifaceted approach. Br Med J. 2007;334:148-151. doi:10.1136/bmj.39050.520069.BE

6. Muhtaseb M, Kalhoro A, Ionides A. A system for preoperative stratification of cataract patients according to risk of intraoperative complications: a prospective analysis of 1441 cases. British J Ophthalmol. 2004;88(10):1242-1246. doi:10.1136/bjo.2004.046003
7. Minassian DC, Reidy A, Desai P, Farrow S, Vafidis G, Minassian A. The deficit in cataract surgery in England and Wales and the escalating problem of visual impairment: epidemiological modelling of the population dynamics of cataract. British J Ophthalmol. 2000;84 (1):4-8. doi:10.1136/bjo.84.1.4

8. Kelly J, Emengo H. Is it clinically and cost effective to perform second-eye cataract surgery in the absence of other ocular co-morbidities in patients who have already had first-eye surgery? Healthcare Improvement Scotland Technol Scoping Report. 2012;8.

9. Narendran N, Jaycock P, Johnston RL, et al. The Cataract National Dataset electronic multicentre audit of 55567 operations: risk stratification for posterior capsule rupture and vitreous loss. Eye. 2009;23 (1):31-37. doi:10.1038/sj.eye.6703049

10. The Royal College of Ophthalmologists. Learning outcomes: surgical Skills SS4. Available from: https://www.rcophth.ac.uk/learningout comes $/ \mathrm{ss} 4 /$.

11. Au L, Saha K, Fernando B, Ataullah S, Spencer F. 'Fast-track' cataract services and diagnostic and treatment centre: impact on surgical training. Eye. 2008;22(1):55-59. doi:10.1038/sj.eye.6702512

12. The Royal College of Ophthalmologists. The way forward: cataract. 2015. Available from: https://www.rcophth.ac.uk/wp-content /uploads/2015/10/RCOphth-The-Way-Forward-Cataract-300117.pdf.

13. Sniatecki JJ, Styles C, Boyle N, Sanders R. Cataract surgery: factors influencing decision to treat and implications for training (South-East Scotland 2008-2014). Clinical Ophthalmol. 2015;9:1821-1827. doi:10.2147/OPTH.S92803

14. Hoffman J, Spencer F, Ezra D, Day AC. Changes in UK ophthalmology surgical training: analysis of cumulative surgical experience 2009-2015. BMJ Open. 2017;7(10):e018526. doi:10.1136/bmjopen-2017-018526

15. Ezra D, Chandra A, Okhravi N, Sullivan P, McDonnell P, Lee J. Higher surgical training in ophthalmology: trends in cumulative surgical experience 1993-2008. Eye. 2010;24:1466-1473. doi:10.1038/eye.2010.54

16. Dean W, Grant S, McHugh J, Bowes O, Spencer F. Ophthalmology specialist trainee survey in the United Kingdom. Eye. 2019;33:917-924. doi:10.1038/s41433-019-0344-z

17. Borooah S, Grant B, Blaikie A, et al. Using electronic referral with digital imaging between primary and secondary ophthalmic services: a long term prospective analysis of regional service redesign. Eye. 2013;27(3):392-397. doi:10.1038/eye.2012.278

18. The Scottish Government. National ophthalmology workstream: hospital eye services, progress, priorities and practical actions for a safe sustainable service across Scotland. ISBN; 978-1-78652-859-9; 2017.

19. Natchlar G, Thulasiraj RD, Meenakshi Sundaram R. Cataract surgery at aravind eye hospitals: 1988-2008. Community Eye Health J. 2008;21(67):40-42.

20. Venkatesh R, Muralikrishnan R, Balent LC, Prakash SK, Prajna NV. Outcomes of high volume cataract surgeries in a developing country. British J Ophthalmol. 2005;89:1079-1083. doi:10.1136/bjo.2004.063479

21. Buchan J. New ways of working: the way forward project 2015-2035 [Internet]. 2016. Available from: https://www.rcophth.ac.uk/wpcontent/uploads/2016/07/08_john_buchan_-_new_ways_of_work ing_7th_june_2016_nhs_england.pdf.

22. Buchan JC, Norman P, Shickle D, Cassels-Brown A, MacEwen C. Failing to plan and planning to fail. Can we predict the future growth of demand on UK eye care services? Eye. 2019;33:1029-1031. doi:10.1038/s41433-019-0383-5

23. The Royal College of Ophthalmologists. RCOphth follow up survey finds continued cataract rationing imposed by CCGs despite NHS Guidance. 2019. Available from: https://www.rcophth.ac.uk/2019/04/ rcophth-follow-up-survey-finds-continued-cataract-rationing-imposedby-ccgs-despite-nice-guidance/?_cldee $=\mathrm{cm} 9$ zaGluaS5zYW5 $\mathrm{kZXJZ}$ QG5ocy5uZXQ\%3D\&recipientid=contact-248cd0451456e41193 f900155d000f0d-faff48ef14474ae481f479fa2ec. 


\section{Publish your work in this journal}

Clinical Ophthalmology is an international, peer-reviewed journal covering all subspecialties within ophthalmology. Key topics include: Optometry; Visual science; Pharmacology and drug therapy in eye diseases; Basic Sciences; Primary and Secondary eye care; Patient Safety and Quality of Care Improvements. This journal is indexed on PubMed

Submit your manuscript here: https://www.dovepress.com/clinical-ophthalmology-journal
Central and CAS, and is the official journal of The Society of Clinical Ophthalmology (SCO). The manuscript management system is completely online and includes a very quick and fair peer-review system, which is all easy to use. Visit http://www.dovepress.com/ testimonials.php to read real quotes from published authors. 